\title{
EDITORIALS
}

\section{Brief Approaches to Alcohol Screening: Practical Alternatives for Primary Care}

\author{
Katharine A. Bradley, MD, MPH ${ }^{1,2,3,5}$, Daniel R. Kivlahan, $P h D^{1,4}$, and Emily C. Williams, $M P H^{1,5}$ \\ ${ }^{1}$ Health Services Research \& Development (HSR\&D), Veterans Affairs (VA) Puget Sound Health Care System, Seattle, WA, USA; ${ }^{2}$ Primary and \\ Specialty Medical Care Service, Veterans Affairs (VA) Puget Sound Health Care System, Seattle, WA, USA; ${ }^{3}$ Department of Medicine, \\ University of Washington, Seattle, WA, USA; ${ }^{4}$ Department of Psychiatry and Behavioral Sciences, University of Washington, Seattle, WA, USA; \\ ${ }^{5}$ Department of Health Services, University of Washington, Seattle, WA, USA.
}

$\mathrm{J}$ Gen Intern Med 24(7):881-3

DOI: $10.1007 / \mathrm{s} 11606-009-1014-9$

(c) Society of General Internal Medicine 2009

$\mathrm{B}$ rief alcohol counseling is one of the most important preventive services we can offer primary care patients. As many as $20 \%$ of general medicine outpatients have unhealthy drinking patterns (definitions ${ }^{1-5}$ in box) and can benefit from brief counseling interventions. ${ }^{6}$ The US Preventive Services Task Force (USPSTF) recommends routine alcohol screening followed by brief interventions (BI), ${ }^{7}$ and in 2006, the National Commission on Prevention Priorities (NCPP) ranked alcohol screening and $\mathrm{BI}$ in the top five U.S. prevention priorities. ${ }^{8}$ NCPP is funded by the US Centers for Disease Control and Agency for Healthcare Research and Quality to prioritize USPSTF recommendations based on the clinically preventable burden of disease and cost effectiveness, and alcohol screening and brief counseling was one of the few preventive interventions that NCPP found to be cost saving. ${ }^{8}$ However, the NCPP also noted that alcohol screening and counseling were among the least implemented recommended interventions studied, and efforts to implement alcohol screening and BI outside research settings have made slow progress.

The first step in implementation of brief alcohol counseling is offering all patients routine alcohol screening. Provider incentives appear to facilitate implementation of screening for unhealthy drinking. ${ }^{9}$ In an effort to encourage screening for unhealthy drinking, the American Medical Association (AMA) has recently developed new Current Procedural Terminology (CPT) codes, as well as a new performance measure for alcohol screening. In 2009, screening for unhealthy alcohol use is one of the measures for the Physician Quality Reporting Initiative (PQRI) implemented by the Center for Medicare and Medicaid Services (CMS), which allows providers to earn an incentive payment of $2 \%$ of their total allowed charges for covered professional services.

Providers and health care systems wishing to implement routine alcohol screening must first select a validated questionnaire, since there is currently no valid laboratory screen for unhealthy drinking. However, choosing which alcohol screening questionnaire to use is not simple. Many alcohol screening questionnaires have been validated over the past 20 years, but those used in randomized trials of BI have included 7-10

Published online June 3, 2009 questions. Given multiple primary care agendas, briefer approaches to screening make routine alcohol screening more practical. However, a favorite questionnaire in the US, the 4item CAGE $^{10}$ (Table 1), is not well-suited to identify patients who can benefit from brief counseling unless questions about alcohol consumption are added. ${ }^{11-13}$ The CAGE questionnaire is a valid screen for alcohol use disorders, but, as pointed out by Smith and colleagues in this issue of JGIM, ${ }^{14}$ the CAGE is not an effective screen for patients with risky drinking who have not experienced problems due to drinking. Moreover, the CAGE asks about drinking ever in the patient's life, and many patients will screen positive who no longer drink alcohol. ${ }^{15}$ Thus, the CAGE should not be used alone for identifying patients who benefit from brief alcohol counseling.

Two brief approaches to screening for unhealthy drinking have been validated over the past decade (Table 1), each of which has strengths in different settings. One approach is single question screens like that validated in the article by Smith and colleagues in this issue of JGIM. ${ }^{2,14}$ The other is the first three questions of the Alcohol Use Disorders Identification Test (AUDIT) developed by the World Health Organization (WHO), ${ }^{16}$ the AUDIT-C. Both single question screens and the AUDIT-C take advantage of the strong association between drinking 5 or more drinks on an occasion and adverse consequences of drinking. ${ }^{17,18}$ Moreover, both brief approaches to screening have performed similarly in US clinical samples. ${ }^{14,19-26}$ Although the study by Smith et al. suggested the AUDIT-C might have a lower sensitivity than the single-question screen recommended by NIAAA, their study included $54 \%$ women and the cut-point they used for the AUDIT-C $(\geq 4)$ is relatively insensitive in women (38\% to $57 \%) .^{20,21}$

Single-question alcohol screens, such as that proposed by NIAAA ("How many times in the past year have you had 4 (women)/5 (men) or more drinks?"), ${ }^{2,14}$ are clearly the optimal approach to integrating screening into clinical history-taking. Single-question screens are brief, easily remembered, and require no scoring. Any report of drinking 4 or more drinks on an occasion for women or 5 or more for men is a positive screen. Moreover, the frequency of drinking at these levels is strongly associated with risk for alcohol dependence, ${ }^{5}$ potentially helping providers to assess patients who will benefit from referral to specialized addictions treatment. For all these reasons, all medical students and general medicine providers should commit to memory one single-question alcohol screen for unhealthy drinking (Table 1).

However, single-item approaches to alcohol screening provide little information on typical or average consumption, an 
Table 1. Screening Questionnaires

CAGE Questionnaire ${ }^{10}$

Screens for alcohol use disorders only; not useful for screening for risky drinking;

possible scores $0-4 ; \geq 2$ points typically considered a positive screen for alcohol use disorders.

C-Have you ever felt you ought to Cut down on your drinking?

A-Have people Annoyed you by criticizing your drinking?

G-Have you ever felt bad or Guilty about your drinking?

E-Have you ever had a drink first thing in the morning (Eye-opener) to steady your nerves or get rid of a hangover?

Single Question Alcohol Screens

Screen for the entire spectrum of unhealthy drinking from risky drinking to alcohol use disorders.

- How many times in the past year have you had $X$ or more drinks?" $(X=4 \text { for women, } 5 \text { for men; ever = positive screen })^{2,14}$

- When was the last time you had more than X drinks in a day?" (X= 4 for women, 5 for men; $<3$ months $=$ positive screen ${ }^{22-24}$

- On any single occasion in the past 3 months have you had more than 5 drinks containing alcohol?" (ever $=$ positive screen) ${ }^{26}$

- How often did you drink 6 or more drinks on an occasion in the past year? (ever $=$ positive screen) ${ }^{19-21}$

- How often did you drink 4 or more drinks on an occasion in the past year? (gender-specific version of the question above; ever $=$ positive screen) ${ }^{20}$

The Alcohol Use Disorders Identification Test Consumption Questions (AUDIT-C) ${ }^{19-21,25,34}$

Screens for the entire spectrum of unhealthy drinking from risky drinking to alcohol use disorders;

possible scores $0-12 ; \geq 3$ points for women or $\geq 4$ for men typically considered a positive screen.

1. How often have you had a drink containing alcohol in the last year? Consider a "drink" to be a can or bottle of beer, a glass of wine, a wine cooler, or one cocktail or shot of hard liquor (like scotch, gin, vodka). Never (0 points); monthly or less (1); $2-4 \times /$ month (2); $2-3 \times /$ week (3); $\geq$

4 days/week (4).

2. How many drinks containing alcohol did you have on a typical day when you were drinking in the last year? I do not drink ( 0 points); $1-2$ drinks (0); 3-4 drinks (1); 5-6 drinks (2); 7-9 drinks (3); 10 or more drinks (4).

3. How often in the last year have you had 6 or more drinks on one occasion? Never ( 0 points); < monthly (1); monthly (2); weekly (3); daily or almost (4)

important component of risky drinking. Women and men can drink up to 3 and 4 drinks daily, respectively, and honestly answer "never" to single question screens, thereby screening negative even though drinking 3-4 drinks daily is associated with increased risk for a number of medical problems including hypertension, liver disease, stroke, trauma, and breast cancer. In addition, many providers are more comfortable first assessing whether patients drink alcohol at all and then asking a single question screen (making screening a two-step approach). In this situation, a validated standard question should be used such as, "Do you sometimes have a drink containing alcohol?"2,14 or, "How often did have you have a drink containing alcohol in the past year?" which is the first question of the AUDIT-C. Non-standard approaches can miss up to $24 \%$ of drinkers. ${ }^{27}$

The three-item AUDIT-C has several advantages for health care systems, clinics, or practices implementing routine alcohol screening with the aid of patient-completed health questionnaires, computerized prompts in an electronic medical record, or web-based personal health risk assessments. The AUDIT-C provides clinicians with information on typical drinking as well as the frequency of heavy drinking, thus providing information on both components of risky drinking (definitions box). The AUDIT-C score (0-12 points) also reflects severity of symptoms due to unhealthy drinking. ${ }^{28}$ In addition, AUDIT-C scores have been associated with increased risk for medication non-adherence (AUDIT-C scores $\geq 4$ ), ${ }^{29}$ hospitalizations for liver disease, upper gastrointestinal bleeding, or pancreatitis ( $\geq 6$ for men in general; $\geq 4$ for men under 50 years old), ${ }^{30}$ fractures $(\geq 8),{ }^{31}$ and death in men under 50 years old $(\geq 10) .{ }^{32}$ Therefore, AUDIT-C scores can assist providers to offer patients personalized feedback on alcoholrelated risks. Such feedback is an essential component of evidence-based brief interventions, along with explicit advice to abstain or drink below recommended limits. ${ }^{7}$ Furthermore, in a recent meta-analysis the AUDIT-C performed as well as the full 10-item AUDIT for identification of unhealthy alcohol use in primary care at recommended cut-points: AUDIT-C sensitivity $0.86(0.79-0.91)$ and specificity $0.78(0.62-0.89)$ compared with the AUDIT sensitivity $0.81(0.75-0.85)$ and specificity $0.83(0.79-0.87),{ }^{33}$ with no significant difference in their overall accuracy. Finally, when AUDIT-C scores from annual screening are stored in electronic medical records, they may be used to monitor changes in risk over time.

However, in settings without electronic health records or web-based methods to facilitate and automate screening, scoring the 3 AUDIT-C items (each scored 0-4) may be a barrier, particularly if the number of response options to AUDIT-C questions is increased. ${ }^{34}$ Another important limitation is that patients can screen positive despite reporting drinking within recommended limits. The screening cut-points of the AUDIT-C are based on empiric findings from interview validation studies and take into account the fact that patients tend to under-report their typical drinking on AUDIT-C questions \#1-2. Therefore, patients reporting 1 drink daily, a level often associated with improved cardiovascular health, can screen positive with an AUDIT-C score of 4 by scoring 4 points on AUDIT-C question \#1 and 0 points on AUDIT-C questions $\# 2-3$. Thus, while the AUDIT-C score is a valid and effective screen, and a useful reflection of overall alcohol-related risks, clinicians must be educated that the reported consumption on AUDIT-C questions \#1-2 tends to underestimate typical drinking. Clinicians might be urged to view the AUDIT-C score as a marker similar to hemoglobin Alc, a tool which does not directly measure specific patient behaviors but provides useful information on patients' alcohol-related risks based on the epidemiologic evidence.

In summary, two brief approaches to alcohol screeningsingle question screens and the AUDIT-C-perform similarly for identifying unhealthy alcohol use and are likely most useful in different settings. All medical providers should commit to memory a validated single question screen for use in medical interviews. The question recommended by NIAAA and validated in this edition of JGIM is one such question and provides 
useful information on the frequency of episodic drinking above recommended daily limits, which is strongly associated with the risk of alcohol dependence. When health care systems implement routine alcohol screening using standardized or automated approaches, the AUDIT-C can provide added useful information on patients' self-reported typical drinking, as well as additional information on the likely burden of alcoholrelated symptoms and alcohol-related health risks.

\section{Box 1. Definitions}

- Unhealthy drinking refers to the entire spectrum from risky drinking to severe alcohol dependence. ${ }^{1}$

- Risky drinking ${ }^{2}$ refers to drinking at levels associated with increased risk for harm:

For men: over 14 drinks per week or 5 or more drinks on any occasion For women: over 7 drinks per week or 4 or more drinks on any occasion. - Alcohol use disorders are defined by DSM-IV ${ }^{3}$ as alcohol abuse or dependence, although recent evidence suggests that symptoms designated as criteria for alcohol abuse may be indistinguishable from those designated as criteria for alcohol dependence. ${ }^{4,5}$

Corresponding Author: Katharine A. Bradley, MD, MPH; VA Puget Sound Health Care System, 1100 Olive Way, Suite 1400, Seattle, WA 98101, USA (e-mail: Katharine.bradley@va.gov).

\section{REFERENCES}

1. Saitz R. Clinical practice, Unhealthy alcohol use. N Engl J Med 2005;352(6):596-607.

2. National Institute on Alcohol Abuse and Alcoholism, US Department of Health and Human Services, National Institute of Health. Helping Patients Who Drink Too Much: A Clinician's Guide (updated 2005 guide). 2007.

3. American Psychiatric Association. Diagnostic and Statistical Manual of Mental Disorders. 4th ed. Washington D.C.: American Psychiatric Association; 1994

4. Saha TD, Chou SP, Grant BF. Toward an alcohol use disorder continuum using item response theory: results from the National Epidemiologic Survey on Alcohol and Related Conditions. Psychol Med. 2006;36(7):931-41.

5. Saha TD, Stinson FS, Grant BF. The role of alcohol consumption in future classifications of alcohol use disorders. Drug Alcohol Depend. 2007;89(1):82-92.

6. Kaner E, Beyer F, Dickinson H, Pienaar E, Campbell F, Schlesinger C, Heather N, Saunders J, Burnand B. Effectiveness of brief alcohol interventions in primary care populations. Cochrane Database Syst Rev. 2007;(2):CD004148.

7. Whitlock EP, Polen MR, Green CA, Orleans T, Klein J. Behavioral counseling interventions in primary care to reduce risky/harmful alcohol use by adults. A summary of the evidence for the U. S. Preventive Services Task Force. Ann Intern Med. 2004;140:557-68.

8. Solberg LI, Maciosek MV, Edwards NM. Primary care intervention to reduce alcohol misuse ranking its health impact and cost effectiveness. Am J Prev Med. 2008;34(2):143-152.

9. Bradley KA, Williams EC, Achtmeyer CE, Volpp B, Collins BJ, Kivlahan DR. Implementation of evidence-based alcohol screening in the Veterans Health Administration. Am J Manag Care. 2006;12 (10):597-606

10. Ewing JA. Detecting alcoholism: the CAGE questionnaire. JAMA 1984;252:1905-07.

11. Wallace $\mathbf{P}$, Haines A. Use of a questionnaire in general practice to increase the recognition of patients with excessive alcohol consumption. BMJ. 1985;290:1949-1952.
12. Fleming MF, Barry KL. A three-sample test of a masked alcohol screening questionnaire. Alcohol Alcohol. 1991;26(1):81-91.

13. Bradley KA, Bush KR, McDonell MB, Malone T, Fihn SD. Screening for problem drinking: comparison of CAGE and AUDIT. Ambulatory Care Quality Improvement Project (ACQUIP). Alcohol Use Disorders Identification Test. J Gen Intern Med. 1998;13(6):379-88.

14. Smith PC, Schmidt SM, Allensworth-Davies D, Saitz R. Primary Care Validation of a Single-Question Alcohol Screening Test. J Gen Intern Med. doi:10.1007/s11606-009-0928-6 JULY 2009.

15. Bradley KA, Maynard C, Kivlahan DR, McDonell MB, Fihn SD. The relationship between alcohol screening questionnaires and mortality among male veteran outpatients. J Stud Alcohol. 2001;62(6):826-33.

16. Saunders JB, Aasland OG, Babor TF, De la Fuente JR, Grant $M$. Development of the Alcohol Use Disorders Identification Test (AUDIT): WHO collaborative project on early detection of persons with harmful alcohol consumption - II. Addiction. 1993;88:791-804.

17. Wechsler H, Davenport A, Dowdall G, Moeykens B, Castillo S. Health and behavioral consequences of binge drinking in college: a national survey of students at 140 campuses. JAMA. 1994;272(21):1672-77.

18. Dawson DA, Li TK, Grant BF. A prospective study of risk drinking: at risk for what? Drug Alcohol Depend. 2008;95(1-2):62-72.

19. Bush K, Kivlahan DR, McDonell MB, Fihn SD, Bradley KA. The AUDIT alcohol consumption questions (AUDIT-C); an effective brief screening test for problem drinking. Ambulatory Care Quality Improvement Project (ACQUIP). Alcohol Use Disorders Identification Test. Arch Intern Med. 1998;158(16):1789-95.

20. Bradley KA, Bush KR, Epler AJ, Dobie DJ, Davis TM, Sporleder JL, Maynard C, Burman ML, Kivlahan DR. Two brief alcohol-screening tests From the Alcohol Use Disorders Identification Test (AUDIT), validation in a female Veterans Affairs patient population. Arch Intern Med. 2003;163(7):821-29.

21. Bradley KA, DeBenedetti AF, Volk RJ, Williams EC, Frank D, Kivlahan DR. AUDIT-C as a brief screen for alcohol misuse in primary care. Alcohol Clin Exp Res. 2007;31(7):1208-17.

22. Williams R, Vinson DC. Validation of a single screening question for problem drinking. J Fam Pract. 2001;50(4):307-12.

23. Canagasaby A, Vinson DC. Screening for hazardous or harmful drinking using one or two quantity-frequency questions. Alcohol Alcohol. 2005;40(3):208-13.

24. Seale JP, Boltri JM, Shellenberger S, Velasquez MM, Cornelius M, Guyinn M, Okosun I, Sumner H. Primary care validation of a single screening question for drinkers. J Stud Alcohol. 2006;67(5):778-84.

25. Frank D, DeBenedetti AF, Volk RJ, Williams EC, Kivlahan DR, Bradley KA. Effectiveness of the AUDIT-C as a screening test for alcohol misuse in three race/ethnic groups. J Gen Intern Med. 2008;23(6):78187.

26. Taj N, Devera-Sales A, Vinson DC. Screening for problem drinking: does a single question work. J Fam Pract. 1998;46(4):328-35.

27. Hawkins EJ, Kivlahan DR, Williams EC, Wright SM, Craig T, Bradley KA. Examining quality issues in alcohol misuse screening. Subst Abus. 2007;28(3):53-65.

28. Bradley KA, Kivlahan DR, Zhou XH, Sporleder JL, Epler AJ, McCormick KA, Merrill JO, McDonell MB, Fihn SD. Using alcohol screening results and treatment history to assess the severity of at-risk drinking in Veterans Affairs primary care patients. Alcohol Clin Exp Res. 2004;28(3):448-55.

29. Bryson CL, Au DH, Sun H, Williams EC, Kivlahan DR, Bradley KA. Alcohol Screening Scores and Medication Nonadherence: A Cohort Study. Annals of Internal Medicine. 2008;149(11):795-803.

30. Au DH, Kivlahan DR, Bryson CL, Blough D, Bradley KA. Alcohol Screening Scores and Risk of Hospitalizations for GI Conditions in Men. Alcohol Clin Exp Res. 2007;31(3):443-51.

31. Harris AHS, Bryson CL, Sun H, Blough DK, Bradley KA. Alcohol Screening Scores Predict Risk of Subsequent Fractures. Substance Use and Misuse. In press.

32. Kinder LS, Bryson CL, Sun H, Williams EC, Bradley KA. Alcohol screening scores and all-cause mortality in male Veterans Affairs patients. J Stud Alcohol Drugs. 2009;70(2):253-60.

33. Kriston L, Holzel L, Weiser AK, Berner MM, Harter M. Meta-analysis: are 3 questions enough to detect unhealthy alcohol use. Ann Intern Med. 2008;149(12):879-88.

34. Seale JP, Shellenberger S, Tillery WK, Boltri JM, Vogel R, Barton B, McCauley M. Implementing alcohol screening and intervention in a family medicine residency clinic. Subst Abus26. 2005;26(1):23-31. 